\title{
CARACTERÍSTICAS DEL YOGURT BATIDO DE FRESA DERIVADAS DE DIFERENTES PROPORCIONES DE LECHE DE VACA Y CABRA ${ }^{1}$
}

\author{
Wendy Natalia Rojas-Castro ${ }^{2}$, Alejandro Chacón-Villalobos ${ }^{3}$, María Lourdes Pineda-Castro ${ }^{4}$
}

\begin{abstract}
RESUMEN
Características del yogurt batido de fresa derivadas de diferentes proporciones de leche de vaca y cabra. Durante 2004, en San José, se evaluó el efecto de diferentes proporciones de leche de cabra (c) y leche de vaca (v) $(0 \% \mathrm{c} / 100 \% \mathrm{v}, 30 \% \mathrm{c} / 70 \% \mathrm{v}, 50 \% \mathrm{c} / 50 \% \mathrm{v}, 70 \% \mathrm{c} / 30 \% \mathrm{v}$ y $100 \% \mathrm{c} / 0 \% \mathrm{v}$ ), sobre el $\mathrm{pH}$, la viscosidad y la sinéresis de un yogurt batido de fresa, durante los días 1, 7, 14 y 21 de almacenamiento en refrigeración a $4-5^{\circ} \mathrm{C}$. $\mathrm{El} \mathrm{pH}$ disminuyó en almacenamiento acentuadamente en los primeros siete días e indistintamente para todas formulaciones $(\mathrm{p} \leq 0,05)$ desde ámbitos iniciales de 4,35-4,40 hasta 4,25-4,30. Durante los primeros siete días aumentó la viscosidad de todas las muestras, para posteriormente descender hasta el día 21. Las muestras con $100 \%$ leche de cabra presentaron menor viscosidad $(\mathrm{p} \leq 0,05)($ media $=11277 \mathrm{cp})$ que las elaboradas con $100 \%$ leche de vaca $($ media $=19979 \mathrm{cp})$. La sinéresis para todas las muestras descendió con el tiempo. La muestra de mayor sinéresis durante todo el periodo fue la de $100 \%$ leche de vaca $($ media $=9,4 \%)$, mientras la de menor fue la de $100 \%$ cabra (media $=2,1 \%$ ). Para la sinéresis se encontró una interacción significativa $(\mathrm{p} \leq 0,05)$ entre el día de almacenamiento y el tipo de leche, concluyéndose que la sinéresis disminuyó con el tiempo y con el mayor contenido de leche de vaca. Se evaluó con 105 jueces el efecto de diferentes formulaciones $(30 \% \mathrm{c} / 70 \% \mathrm{v}, 50 \% \mathrm{c} / 50 \% \mathrm{v}$, $70 \% \mathrm{c} / 30 \% \mathrm{v}$ y $100 \% \mathrm{c} / 0 \% \mathrm{v})$, sobre el agrado general así como la aceptación del color y textura. La formulación de mayor agrado global $(\mathrm{p} \leq 0,05)$ fue la de $30 \%$ leche de cabra, que en promedio alcanzó un valor de 8,1 en una escala hedó-

nica híbrida $10 \mathrm{~cm}$.
\end{abstract}

\begin{abstract}
Characteristics of stirred strawberry yogurt derived from different proportions of cow and goat milk. During 2004, in San José, we evaluated the effect of several proportions of cow (c) and goat milk (g) $(0 \% \mathrm{~g} / 100 \% \mathrm{c}$, $30 \% \mathrm{~g} / 70 \% \mathrm{c}, 50 \% \mathrm{~g} / 50 \% \mathrm{c}, 70 \% \mathrm{~g} / 30 \%$ y $100 \% \mathrm{~g} / 0 \% \mathrm{c}$ ), upon $\mathrm{pH}$, viscosity, and syneresis of a stirred strawberry yogurt during day $1,7,14$ and 21 of refrigerated storage at $4-5^{\circ} \mathrm{C}$. The $\mathrm{pH}$ decreased indistinctly $(\mathrm{p} \leq 0.05)$ and notoriously by day seven for all samples, from initial values of 4.40-4.35 to final ones of 4.30-4.25. Viscosity of all samples increased during the first seven days only and then declined until day 21. Samples with $100 \%$ goat milk showed less viscosity (mean of $11277 \mathrm{cp}$ ) when compared with those with $100 \%$ cow milk (mean of $19979 \mathrm{cp}$ ). Syneresis decreased for all samples as storage time increased. The sample with the highest syneresis rate during the whole storage period was the one with $100 \%$ cow milk (9.4\% average). In contrast, yogurt with $100 \%$ goat milk showed the lowest syneresis rate $(2.1 \%$ average). A significant interaction $(\mathrm{p} \leq 0.05)$ between storage time and milk type was found, which implies that syneresis diminishes with storage time and as cow milk content increases in the formulation. The effect of several formulations $(30 \% \mathrm{~g} / 70 \% \mathrm{c}, 50 \% \mathrm{~g} / 50 \% \mathrm{c}, 70 \% \mathrm{~g} / 30 \% \mathrm{c}$ y $100 \% \mathrm{~g} / 0 \% \mathrm{c}$ ) upon general acceptance, color an texture was evaluated using 105 consumers. The formulation with the highest general acceptance was the one with $30 \%$ goat milk, with an average value of 8.1 in a $10 \mathrm{~cm}$ hedonic scale.
\end{abstract}

Key words: Dairy products, goat milk, yogurt, viscosity, liking.

Palabras claves: Productos lácteos, leche de cabra, yogurt, viscosidad, agrado.

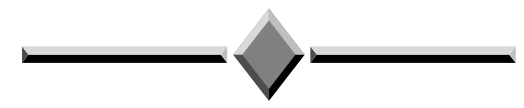

1 Recibido: 8 de agosto, 2006. Aceptado: 29 de agosto, 2007. Inscrito en Vicerretoría de Investigación N No 737-A4-040, Universidad de Costa Rica.

2 Empresa privada. Correo electrónico: wenrc16@yahoo.es

3 Estación Experimental Alfredo Volio Mata. Facultad de Ciencias Agroalimentarias. Universidad de Costa Rica. Cartago, Costa Rica. Correo electrónico:achaconv@cariari.ucr.ac.cr

4 Escuela de Tecnología de Alimentos. Facultad de Ciencias Agroalimentarias.Universidad de Costa Rica. San José, Costa Rica. Correo electrónico:mlpineda@cariari.ucr.ac.cr 


\section{INTRODUCCIÓN}

La leche está constituida por una mezcla variable y compleja de diversos constituyentes de alto valor nutritivo de gran importancia industrial (Keating y Gaona 1999). La leche de algunas especies como la de vaca y la de cabra se utilizan como un importante alimento para los humanos por su calidad nutricional (Brito 2000) al ser fuente de proteínas y de vitaminas (A, D, $\mathrm{B}_{1}, \mathrm{~B}_{2} \mathrm{y} \mathrm{B}_{12}$, principalmente).

La leche de vaca es la de mayor disponibilidad en el mundo occidental, contando con la mayor popularidad, así como los productos derivados de ésta (Keating y Gaona 1999). Su contenido en de vitamina $B_{12}$ es cinco veces más que en la leche de cabra y el ácido fólico es 12 veces mayor (Dostalova 1994), mientras que en el caso de la leche de cabra sus proteínas son menos alergénicas y su grasa es más digerible al ser el glóbulo graso de menor tamaño (Haenlein et al. 1992). Wetherbee (2002) menciona que esta última cualidad influye positivamente en las características sensoriales de los productos elaborados a partir de leche de cabra.

En razón de lo anterior, y analizando las ventajas antes mencionadas, se puede especular que un producto elaborado a partir de ambas leches puede contribuir no solo a satisfacer muchas necesidades nutricionales si no que por otro lado, puede ofrecer una opción interesante y competitiva al pequeño y mediano productor que desee comercializar productos innovadores.

Durante los últimos años el consumidor a nivel mundial ha desarrollado una marcada tendencia por los productos naturales y saludables (Perdigón et al. 2002), tal y como es el caso del yogurt (Norat y Riboli 2003; Crawford 2004), que es el más popular de los productos acidificados de la leche (Buttriss 1997). El consumo del yogurt implica de hecho importantes beneficios para la salud, entre los cuales pueden citarse el ser una buena fuente de vitamina $\mathrm{B}_{12}$, ácido fólico y potasio (Crawford 2004); el incremento en la biodisponibilidad de nutrientes como el magnesio, el zinc, calcio y fósforo (Palencia 2004), y la mejor absorción de la lactosa hidrolizada (Perdigón et al. 2002); así como una excelente digestibilidad derivada de lo fácilmente metabolizable que es su fino coágulo por las enzimas digestivas (Palencia
2004) que es fuente de proteínas de excelente calidad (Mora 1994). Según indican Horst et al. (1995), los microorganismos involucrados en la producción del yogurt (Streptococcus salivarius subsp. thermophilus y Lactobacillus delbrueckii subsp. bulgaricus) poseen una actividad antimicrobiana que inhibe patógenos, además de estar asociados con una posible disminución en la colesterolemia y del riesgo de cáncer de colon.

De los diferentes tipos de yogurt que se pueden encontrar en el mercado costarricense, la categoría de yogurt batido es la más popular, dado su alto consumo asociado a su mayor aceptación (Carvajal 1999). En adición a lo anterior se afirma que el yogurt con sabor a fruta posee una posición importante dentro de la amplia gama de productos lácteos (Dengler y Kratz 1995). De hecho, Claverán (1993) señala que una gran parte de la reciente expansión en el consumo de yogurt se debe al uso de frutas que han mejorado su perfil en cuanto a sabor, textura y presentación. En este sentido, las bases de fruta para yogurt juegan un papel trascendental para los fabricantes de este producto, pues muchos consumidores no gustan del yogurt natural. Entre estas frutas, la fresa ha llegado a ser una de las frutas más utilizadas para la elaboración de yogurt, pues, según estudios realizados por Ferraro (1982), esta fruta es preferida por su sabor y por su calidad nutricional.

Uno de los atributos de gran importancia en el yogurt es la textura (Shoemaker et al. 1992), que suele percibirse en términos de la viscosidad, y cuya medición es muy importante sobre todo en productos que se supone deben tener una cierta consistencia en relación con su aspecto o paladar, como lo es el yogurt (Lewis 1993). Se suman además otros factores como el sabor, la apariencia, el $\mathrm{pH}$, y el valor nutricional (Rao et al. 1987; Rodríguez et al. 1994; Sherman 1979; Rasic y Kurmann 1978; Dengler y Kratz 1995; Posecion et al. 2005).

Varios factores influyen en las propiedades reológicas del yogurt, entre ellos el tipo de animal que generó de leche empleada en su elaboración (Keating y Gaona 1999), la composición de la leche en términos de la estructura de los ácidos grasos (Hirano et al. 1998, Haenlein et al. 1992), las caseínas presentes, el contenido de vitaminas, de lactosa y de minerales. 
Las diferencias existentes entre el contenido de materia seca en la leche de cabra y de vaca producen, de hecho, contrastes en las viscosidades de los yogures producidos a partir de ambas leches (Bille et al. 2000). Se han observado también variaciones en el $\mathrm{pH}$ de los productos de acuerdo con las diferencias bioquímicas entre la leche de cabra y de vaca (Haenlein et al. 1992). Este parámetro es de gran importancia ya que puede llegar a influenciar no sólo la viscosidad estructural y la firmeza del producto sino también su sabor (Sherman 1979). En cuanto a las caseínas, su composición y estructura son de gran interés pues la matriz proteica del yogurt consiste básicamente de cadenas cortas y ramificadas de micelas de caseína (Steiner y Volansky 2003). Según menciona Haenlein et al. (1992), entre la leche de cabra y vaca existen diferencias en el tipo y tamaño de los agregados de caseína, lo cual puede influir en la estructura del gel.

El éxito de cualquier producto alimenticio se sustenta no sólo en la calidad nutricional, sino también en sus características sensoriales, que son las que definen su aceptabilidad en el mercado (Sabbag y Gosta 1995). No existe ningún otro instrumento que pueda reproducir o reemplazar la respuesta humana; por lo tanto, la evaluación sensorial resulta un factor esencial en cualquier estudio sobre alimentos, sobre todo si se trata de desarrollar o mejorar algún producto (Watts et al. 1992; Sabbag y Gosta 1995).

En vista de que el bajo contenido de caseína y los cambios estacionales en la composición dificultan la producción de yogurt de leche de cabra con una consistencia apropiada (Farnsworth et al. 2002), la producción de yogurt con mezcla de leches de cabra y de vaca se presenta como una posible solución a este problema. Sin embargo, en la literatura, difícilmente se encuentran estudios en que se haya evaluado la utilización de la leche de cabra mezclada con leche de otras fuentes, en la preparación de yogurt. El artículo de Uysal et al. (2003) menciona una experiencia anterior de sustitución utilizando la ultrafiltración como método de fortificación. Por otra parte, Merin (2000) indica que el yogurt preparado con la leche de cabras alimentadas por pastoreo es más rico en sólidos y tiene una viscosidad mayor en comparación con el yogurt de leche de vaca o el de cabras alimentadas en espacios cerrados. Debido a la poca información disponible en este tópico y a las contradicciones encontradas con respecto a la consistencia del yogurt de leche de cabra, el presente trabajo tiene la finalidad de contribuir en la investigación de alternativas de aprovechamiento de la leche de cabra, ofreciendo la posibilidad de diversificar opciones de producción y de oferta al consumidor. Es pues el objetivo concreto evaluar el efecto de diferentes proporciones de leche de vaca y leche de cabra sobre las características químicas, físicas y sensoriales de un yogurt batido de fresa, con el fin de establecer una formulación aceptable para el gusto del consumidor costarricense.

\section{MATERIALES Y MÉTODOS}

\section{Localización del estudio}

Este estudio se realizó durante el segundo semestre del año 2004. Los análisis fisicoquímicos y las corridas experimentales se efectuaron en el laboratorio de química y modulo lácteo de la Estación Experimental de Ganado Lechero Alfredo Volio Mata (EEAVM), ubicada en el Alto de Ochomogo en Cartago, los laboratorios y planta piloto del Centro Nacional de Ciencia y Tecnología de Alimentos (CITA), y los laboratorios de la Escuela de Tecnología de Alimentos de la Universidad de Costa Rica (ETA). Estas dos últimas unidades académicas están ubicadas en la sede Rodrigo Facio de la Universidad de Costa Rica, San José.

\section{Formulación y elaboración de los yogures sustitui- dos}

Para la elaboración del yogurt base se adaptó la formulación general citada por ASEAL (2004b), con las modificaciones mostradas en el Cuadro 1. El proceso seguido es detallado en la Figura 1. Las cantidades elaboradas y el número de repeticiones se discuten en las secciones de análisis fisicoquímico y de diseño experimental.

Se utilizó en las elaboraciones leche fresca de vaca (Bos taurus) de raza "Jersey" y de cabra (Capra hircus) de raza "Lamancha", procedente de la EEAVM y con menos de seis horas de ordeño. Ambas leches fueron analizadas por el método Snap 
Cuadro 1. Formulación base del yogurt natural batido $(3,1 \%$ grasa). San José, Costa Rica. 2005.

\begin{tabular}{lc}
\hline \multicolumn{1}{c}{ Ingrediente } & Porcentaje (\% m/m) \\
\hline Leche descremada fluida de cabra y/o & \\
vaca (0,1\% grasa) & 88,6 \\
Crema de leche de vaca (40\% grasa) & 3,75 \\
Crema de leche de cabra (40\% grasa) & 3,75 \\
Leche en polvo descremada & 2,4 \\
Estabilizante CC-76223 & 1,5 \\
Cultivo iniciador & $\mathrm{SEF}^{*}$ \\
\hline
\end{tabular}

*Según especificaciones del fabricante, dependiendo de la cantidad de cultivo contenida en el sobre.

(Gonzáles $2003^{5}$ ) para garantizar que estaban libres de antibióticos. Además se evaluó la acidez titulable expresada como ácido láctico (ATECAL) y el peso específico por medio de la metodología citada por Chacón (2004). Lo anterior para garantizar muestras con un valor de ATECAL menor a $0,18 \%$ y peso específico mayor a 1,028 , que es lo recomendado por la bibliografía para leche destinada a la elaboración de derivados lácteos (Chacón 2003). Hasta el momento del descremado la leche se mantuvo en refrigeración a una temperatura de $4^{\circ} \mathrm{C}$.

Con el fin de realizar la estandarización de sólidos totales de la leche a procesar, se procedió a determinar el contenido de dichos sólidos en la leche previamente a la operación de descremado. Lo anterior se efectuó en forma instrumental empleando un analizador de leche marca EKO-MILK ${ }^{\circledR}$ modelo standard. Éste proporcionó, además de la información del contenido de sólidos totales, el porcentaje de grasa de la leche.

Se realizó a continuación la separación de la leche y la crema, independientemente para cada tipo de leche. Para ello se llevó las muestras a una temperatura de 30$35^{\circ} \mathrm{C}$ empleando una marmita Groen ${ }^{\circledR}$ de 40 litros modelo DN/TA-10SP de doble chaqueta, calentada por vapor. El calentamiento tiene el fin de garantizar una distribución homogénea de la grasa. Se hizo uso a continuación

5 GONZÁlES, A. 2003. Evaluación de antibióticos en leche empleando el método Snap. INDULAC. San José, Costa Rica. Comunicación personal.

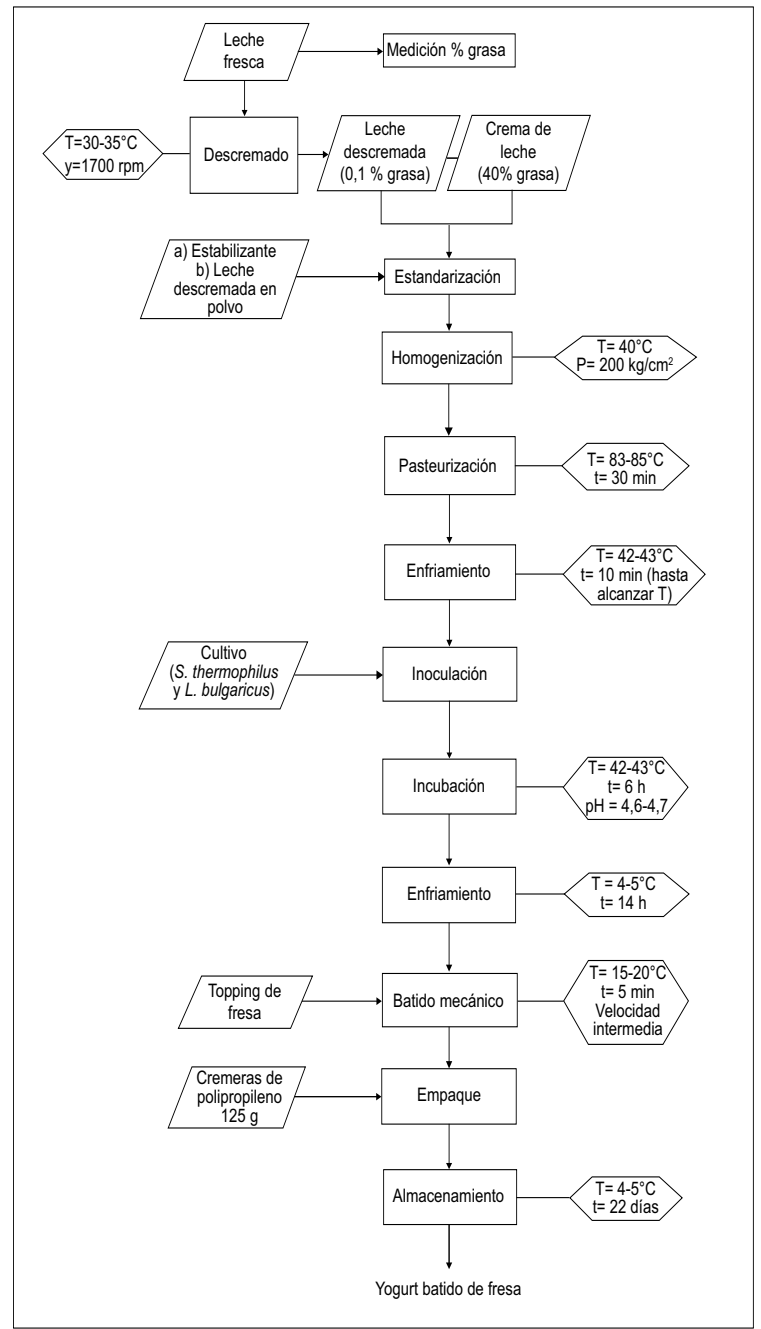

Figura 1. Flujo de proceso para la elaboración de yogurt batido de fresa. San José, Costa Rica. 2005.

de una descremadora mecánica marca Alfa-Laval ${ }^{\circledR}$ modelo 29AE a una velocidad de $1.700 \mathrm{rpm}$. La leche y la crema obtenidas contenían una cantidad de grasa aproximada de $0,1 \%$ y $40 \%$, respectivamente.

Para estandarizar la leche, la crema se mezcló con la leche descremada considerando un balance de materiales para obtener un contenido de grasa de 3,1\% en ambos casos. Se añadió a la vez la leche descremada en polvo de la marca comercial Dos Pinos ${ }^{\circledR}$, así como estabilizante CC-76223 (almidón modificado, 
gelatina, pectina y sulfato de calcio) distribuido por la compañía Aseal y según sus especificaciones. De esta manera se ajustó el contenido de sólidos no grasos a $10,6 \%$ en ambos tipos de leche.

Las mezclas obtenidas se homogenizaron seguidamente a una temperatura de $40^{\circ} \mathrm{C}$ y a una presión de $200 \mathrm{~kg} / \mathrm{cm}^{2}$, en un homogenizador marca General Electric ${ }^{\circledR}$ modelo 5K182-AL214B.

Hasta esta etapa, y como se ha detallado, se realizaron las operaciones por separado para cada tipo de leche. Una vez obtenidas ambas leches estandarizadas al 3,1\% de grasa y $10,6 \%$ de sólidos no grasos, según recomienda Carvajal (1999), y después de homogenizadas, se procedió a realizar las mezclas de las diferentes proporciones de ambos tipos de leche para la elaboración del yogurt (Uysal et al. 2003), tal y como se muestra el Cuadro 2.

Cuadro 2. Porcentajes de mezclado de leche de cabra y vaca estandarizadas al 3,1\% de grasa y 10,6\% de sólidos no grasos utilizados en la elaboración de las diferentes sustituciones de yogurt batido. San José, Costa Rica. 2005.

\begin{tabular}{ccc}
\hline \multirow{2}{*}{ Formulación } & \multicolumn{2}{c}{ Porcentaje de leche a utilizar $(\%)$} \\
\cline { 2 - 3 } & \multicolumn{2}{c}{ Cabra } \\
\hline & 0 & Vaca \\
A & 30 & 100 \\
B & 50 & 70 \\
C & 70 & 50 \\
D & 100 & 30 \\
E & & 0 \\
\hline
\end{tabular}

Las mezclas obtenidas se pasteurizaron llevándolas a una temperatura de $83-85^{\circ} \mathrm{C}$ durante 30 minutos, siguiendo el procedimiento descrito por Chacón (2003). Con el fin de que las mezclas tuvieran una temperatura adecuada para añadirles un cultivo iniciador, se enfriaron en aproximadamente 10 minutos a modo de choque térmico hasta alcanzar una temperatura de $42-43^{\circ} \mathrm{C}$, utilizando un baño de agua-hielo como medio de enfriamiento. Para llevar a cabo esta operación y en adelante se procedió lo más higiénicamente posible con el fin de no contaminar las mezclas, empleando cubrebocas, delantal y redecilla para el cabello.

Se procedió a la inoculación de las mezclas con el cultivo YC-X11 de la marca comercial Chr Hansen ${ }^{\circledR}$, el cual corresponde a una mezcla de Streptococcus salivarius subsp. thermophilus y Lactobacillus delbrueckii subsp. bulgaricus. Estos preparados son de inoculación directa en el proceso (DVS, Direct Vat Set) y son suministrados en la forma de liofilizado-congelado (Aseal 2004a). Se agregó la cantidad de cultivo recomendada por el fabricante mezclando manualmente con un agitador de acero inoxidable sanitizado y extremando las medidas higiénicas. Las mezclas con el cultivo se incubaron a $42-43^{\circ} \mathrm{C}$ durante aproximadamente seis horas, tiempo en que el yogurt debía adquirir un pH cercano a 4,6-4,7. Esto se efectuó en una incubadora marca Alfa-Laval ${ }^{\circledR}$ modelo 050-07.

Finalizada la etapa de incubación se hizo descender la temperatura con el fin de evitar la elevación posterior de acidez. Se procedió a refrigerar las muestras a $4-5^{\circ} \mathrm{C}$ luego de concluido el tiempo de incubación, durante aproximadamente 14 horas. Después de este periodo se sacaron las muestras de la cámara de refrigeración y se dejaron a temperatura ambiente hasta alcanzar $15-20^{\circ} \mathrm{C}$, que es la temperatura necesaria para el batido. El topping ${ }^{6}$ de fresa $\left(65^{\circ}\right.$ Brix $)$ se incorporó durante el batido en una cantidad de $16,3 \%$ con respecto a la totalidad de la mezcla (Sáenz 1984). Se empleó una batidora industrial marca Silverson ${ }^{\circledR}$ modelo AXR colocando el indicador del aparato en velocidad intermedia por aproximadamente 5 min.

Después de que el producto fue batido, se colocó por dosificación manual en recipientes de polipropileno con tapa autoajustable de $125 \mathrm{~g}$ de capacidad. El producto empacado se colocó en cámaras frigoríficas con una temperatura de $4-5^{\circ} \mathrm{C}$, donde se mantuvo hasta por tres semanas por recomendación de Cortés

\footnotetext{
6 Topping: mermelada de bajo contenido de pectina que funge como recubrimiento o relleno en productos de repostería y heladería.
} 
$\left(2004^{7}\right)$, por ser el período de vida útil del yogurt y durante el cual se efectuaron los análisis.

\section{Análisis de las formulaciones}

\section{Análisis físico-químico}

Para cada repetición se elaboraron $2,0 \mathrm{~kg}$ de cada una de las formulaciones propuestas. De todas las tandas de cada formulación, se tomaron cuatro muestras de $500 \mathrm{~g}$, una para cada tiempo de muestreo (a los 1 , 7,14 y 21 días) y se almacenaron en refrigeración a 4$5^{\circ} \mathrm{C}$. A cada muestra se le realizó la medición de $\mathrm{pH}$, la determinación del grado de sinéresis y la medición de viscosidad, durante el período de almacenamiento en cada tiempo de muestreo.

Se utilizó el método 981.12 (AOAC 1990) para la medición de $\mathrm{pH}$ en productos acidificados, utilizando un pH-metro marca Corning ${ }^{\circledR}$ modelo 430, el cual fue calibrado antes de su uso con buffers de pH 4,01 y 7,00.

La sinéresis expresada como el volumen de suero desprendido durante el almacenamiento se determinó por el método descrito por Mora (1994) y utilizado por Carvajal (1999). Se midió en muestras de yogurt de $50 \mathrm{~g}$ pesadas en una balanza granataria electrónica marca Sartorius y modelo PT6, y que posteriormente se centrifugaron a $3.000 \mathrm{rpm}$ durante 20 minutos a $10^{\circ} \mathrm{C}$, en una centrífuga refrigerada marca IEC-Centra ${ }^{\circledR}$ modelo 7R. El volumen de suero desprendido se determinó trasvasándolo a una probeta de $25 \mathrm{ml}$.

Se definió el método para determinar la viscosidad aparente de las diferentes formulaciones de yogurt producido mediante pruebas preliminares, según las características del gel obtenidas (Pineda 20048). Se empleó el viscosímetro de Brookfield marca ColeParmer ${ }^{\circledR}$ modelo 98936-10, utilizando el husillo ${ }^{\circ} 4$ y a una velocidad de 5,0 rpm. La temperatura de las

7 CORTÉS, M. 2004. Período de vida útil del yogurt. Centro Nacional de Ciencia y Tecnología de Alimentos (CITA), Universidad de Costa Rica. San José, Costa Rica. Comunicación personal.

8 PINEDA, M. 2004. Medición de viscosidad en yogurt. Escuela de Tecnología de Alimentos, Universidad de Costa Rica. San José, Costa Rica. Comunicación personal. muestras fue de $5^{\circ} \mathrm{C}$, que corresponde con la temperatura de almacenamiento.

\section{Análisis sensorial}

Se elaboraron $5,0 \mathrm{~kg}$ de yogurt de cada formulación para la evaluación de la aceptación, la cual se llevó a cabo durante el sétimo día de almacenamiento. Se analizó el agrado de los cuatro tipos de yogurt con leche de cabra, sin incluir el elaborado con $100 \%$ leche de vaca (formulación A). La prueba se efectuó de esta manera debido a que el objetivo primordial fue evaluar la aceptación de los productos con algún grado de sustitución de leche de vaca por leche de cabra (González $2004^{9}$ ) y se conocía de antemano que la población costarricense utilizada para el estudio está más adaptada al sabor de la leche de vaca y a sus productos (Corrales y Chacón 2005). Por lo tanto, si se hubiera incluido la formulación A, se esperaría que la aceptación de los panelistas se inclinara más hacia esta formulación, lo que introduciría un sesgo en los resultados.

El panel estuvo conformado por 105 consumidores de yogurt que no necesariamente consumen yogurt de leche de cabra (52 hombres y 53 mujeres), en edades entre 18 y 60 años, en su mayoría estudiantes y profesionales. Estos datos, que permitieron caracterizar a la población elegida para el estudio, fueron recolectados mediante la aplicación de una pequeña encuesta al consumidor (Cubero 200410).

La medida de la aceptación se hizo mediante una prueba de nivel de agrado, utilizando una escala hedónica híbrida de 10 centímetros de largo (Villanueva et al. 2002), según lo sugerido por Cubero (2004).

Además se realizó una prueba de aceptación en la cual los jueces evaluaron las muestras en dos atributos (color y textura), en una escala Justo-Correcto de cinco categorías, siguiendo la metodología sugerida por Cubero $\left(2004^{10}\right)$.

9 GONZÁLEZ, M. 2004. Diseño experimental y análisis estadístico. USES, Escuela de Estadística, Universidad de Costa Rica. San José, Costa Rica. Comunicación personal.

10 CUBERO, E. 2004. Pruebas orientadas a consumidores. Escuela de Tecnología de Alimentos, Universidad de Costa Rica. .San José, Costa Rica. Comunicación personal. 


\section{Metodología estadística}

\section{Definición del número de repeticiones}

Para obtener el número de repeticiones se efectuó una prueba preliminar donde se cuantificó la variabilidad de la viscosidad como uno de los parámetros más volubles en el yogurt, así como la diferencia mínima de viscosidad a detectar por un grupo de personas. Según las recomendaciones de González (20049), con el fin de obtener la variabilidad se realizaron cinco tandas (repeticiones) de uno de los tratamientos propuestos (formulación A), se midió la viscosidad por triplicado de la manera descrita en el apartado de análisis fisicoquímico, obteniéndose la variabilidad del parámetro expresada como desviación estándar. Se definió la diferencia mínima deseable a detectar como aquella existente entre la viscosidad medida instrumentalmente de un yogurt 100\% leche de vaca y un yogurt $100 \%$ leche de cabra, tal y como lo recomendó Pineda (2004) ${ }^{8}$.

Con la desviación estándar $(3.280 \mathrm{cp})$ y la diferencia mínima a detectar de la viscosidad $(9.430 \mathrm{cp})$, y utilizando un $\alpha$ de 0,05 , se calculó un número de cuatro repeticiones con una potencia de prueba $(1-\beta)$ no menor de 0,7 .

\section{Diseño experimental}

Se utilizó un diseño irrestricto aleatorio con cinco tratamientos determinados por la proporción de leche de cabra del yogurt $(0 \%, 30 \%, 50 \%, 70 \%, 100 \%)$. Para las cuatro repeticiones se prepararon los cinco tipos de sustitución. Cada repetición se preparó a partir de lotes de leche diferentes.

\section{Análisis de los datos}

Los datos de $\mathrm{pH}$, sinéresis y viscosidad obtenidos según el período de almacenamiento y para cada una de las sustituciones de leche utilizadas, se analizaron mediante regresión lineal utilizando el programa Excel de Microsoft ${ }^{\circledR}$ versión XP (González 20049). Además se realizó un análisis de covarianza utilizando el programa JMP ${ }^{\circledR}$ S.A.S. versión 5.0, con el fin de determinar diferencias significativas en los resultados obtenidos. Se aplicó la Prueba de Tukey cuando fue necesario hallar el origen de estas diferencias.
Para analizar los datos del nivel de agrado general se utilizó un análisis de varianza (ANDEVA) de una vía con el programa Excel de Microsoft ${ }^{\circledR}$ versión $\mathrm{XP}$, con el fin de determinar la existencia de diferencias significativas entre el grado de aceptación de las muestras con diferente proporción de las leches (30\%, $50 \%, 70 \%$ y $100 \%$ leche de cabra). A los datos de aceptación de los atributos de color y textura, se les aplicó un análisis de varianza de dos vías, utilizando el mismo programa. En los casos en que se encontraron diferencias significativas, se aplicó una Prueba de Comparación de Medias (Least Significance Difference, LSD) para determinar el origen de las diferencias, de acuerdo a lo recomendado por Cubero $\left(2004^{10}\right)$.

\section{RESULTADOS Y DISCUSIÓN}

\section{Evaluación físico-química del yogurt}

\section{Evaluación del pH de las muestras}

La fermentación es una de las operaciones claves en la tecnología del yogurt. Una vez inoculada la mezcla se inicia una fermentación ácido-láctica por la hidrólisis enzimática de la lactosa en glucosa y galactosa, siendo la glucosa formada posteriormente descompuesta a ácido láctico (Spreer 1998). Esta formación de ácido láctico provoca un descenso en el $\mathrm{pH}$ que tiene lugar no sólo durante la incubación, sino también durante el almacenamiento del yogurt, pues los microorganismos quedan viables, aunque en este último caso el descenso es menos marcado debido al efecto de la baja temperatura.

En la Figura 2 se puede observar el fenómeno del descenso del $\mathrm{pH}$ durante el almacenamiento, para todas las sustituciones de yogurt que se elaboraron. Se puede apreciar como durante los primeros siete días de almacenamiento, el descenso del pH se hace más pronunciado que en los siguientes días, llegando casi a estabilizarse al final del almacenamiento.

Tal y como mencionan Rasic y Kurmann (1978), la actividad metabólica de los microorganismos durante la manufactura del yogurt es reducida considerablemente por el enfriamiento luego de la incubación. 


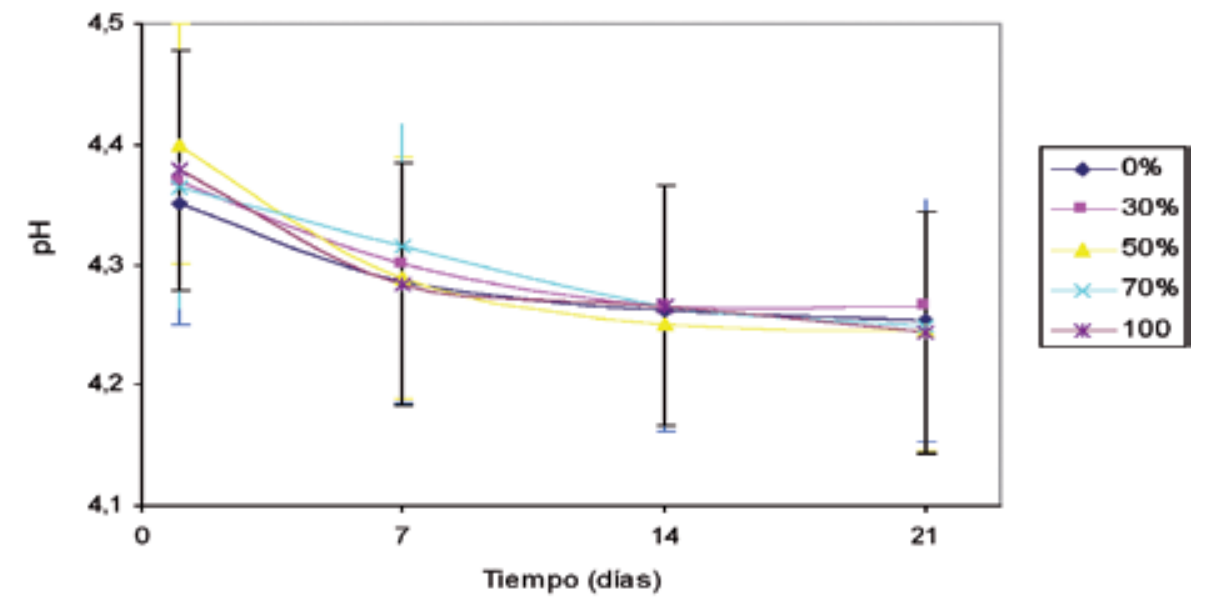

*Se presentan los intervalos de confianza al $95 \%$.

Figura 2. Comportamiento del pH medido durante el tiempo de almacenamiento del yogurt con diferente contenido de leche de cabra. San José, Costa Rica. 2005.

Sin embargo, se sigue desarrollando una acidificación durante el almacenamiento aún a $0-5^{\circ} \mathrm{C}$, porque no es posible detener completamente la actividad enzimática de los cultivos lácteos durante el enfriamiento.

Unido al descenso de la actividad enzimática, y debido a las condiciones de almacenamiento, se da una disminución en la carga bacteriana, y esto también afecta el desarrollo de acidez en el producto. Según Jay (1994), típicamente el yogurt recién elaborado contiene en torno a $10^{9}$ microorganismos/g, pero es posible que durante el tiempo que permanece almacenado el número de microorganismos disminuya hasta $10^{6}$, en especial, cuando se conserva a $5^{\circ} \mathrm{C}$ durante varios días.

El comportamiento del $\mathrm{pH}$ resultó el mismo para todas las diferentes muestras de yogurt y se pudo constatar, mediante el análisis de varianza, que hubo diferencias significativas $(\mathrm{p}<0,05)$ en el $\mathrm{pH}$ de las muestras de acuerdo al día de almacenamiento, es decir, el pH disminuyó significativamente durante el almacenamiento. La actividad microbiana es pues mucho mayor al inicio que al final del almacenamiento, lo que provoca valores de $\mathrm{pH}$ diferentes en cada uno de los días de muestreo.
No se presentaron diferencias significativas $(p>0,05)$ en cuanto al tipo de leche empleada, por lo tanto, la influencia del día de almacenamiento sobre el $\mathrm{pH}$ fue similar en todos los tipos de yogurt elaborados. Por lo que se podría decir que, en las condiciones de este estudio, aunque se utilicen tipos de leche diferente o mezclas de éstas, el comportamiento del $\mathrm{pH}$ del yogurt a lo largo del almacenamiento no será diferente entre las muestras. Este comportamiento puede ser similar porque ambas leches son ricas en lactosa $(3,8$ a 4,3\% en leche de cabra contra 4,9 a 5,5\% en leche de vaca) (Chacón 2005), por lo tanto, ambas leches proveen a los microorganismos de una respetable cantidad de sustrato para la formación de ácido láctico (Spreer 1998). De ésto también se puede deducir que los microorganismos utilizados presentaron una actividad muy similar independientemente del tipo de leche empleada.

El fenómeno de estabilización del $\mathrm{pH}$ de las muestras al final del almacenamiento se debe probablemente a la inhibición de la actividad enzimática de los cultivos y a la disminución en la carga bacteriana, aunque factiblemente se deba también al agotamiento de las reservas de lactosa disponible. Sin embargo, se puede pensar por las condiciones de almacenamiento 
(especialmente la baja temperatura) que es más probable que surja primero la inhibición de la actividad enzimática y el descenso en los microorganismos, antes de que se acabe por completo la lactosa (Tamime y Robinson 1985).

Evaluación de la viscosidad y la sinéresis de las muestras

Se puede observar a priori en la Figura 3 como pareciera registrarse un aumento del valor de la viscosidad en todas las muestras durante los primeros días de almacenamiento (del 1 al 7), seguido, durante los días posteriores (del 7 al 14) y hasta el día 21 por un descenso en este parámetro para todas las formulaciones.

Tal y como lo explican Rasic y Kurmann (1978), durante los primeros días de almacenamiento en refrigeración ocurre una mejora en la consistencia y viscosidad del yogurt que está relacionada con la solidificación en la estructura del gel durante el enfriamiento y la eventual tixotropía ${ }^{11}$ del yogurt batido. En unos días, el yogurt en refrigeración pierde su consistencia óptima porque la solidificación estructural tiene lugar durante un cierto intervalo de tiempo (aproximadamente en los primeros 10 días de almacenamiento).

Otro factor que ayuda al incremento de la viscosidad es la presencia de pectinas. Cuando el yogurt contiene frutas ricas en pectina, se presenta un fuerte incremento en la consistencia durante los primeros 10 días de almacenamiento debido a la hidratación de las pectinas abundantes en la fresa y por ende en el topping (Karagul-Yüceer $e t$ al. 2001; White 2002; Saint-Eve et al. 2006).

El análisis estadístico encontró que el tiempo de almacenamiento no tiene efecto significativo $(\mathrm{p}>0,05)$ sobre la viscosidad. No obstante, sí se encontraron diferencias significativas en viscosidad $(\mathrm{p}<0,05)$ de acuerdo al tipo de leche empleada. En la Figura 3 se aprecia claramente que la mayor viscosidad la presentó el yogurt elaborado con $100 \%$ leche de vaca durante todo el almacenamiento; por el contrario, la muestra con la menor viscosidad fue la del yogurt con $100 \%$ leche de cabra. Este efecto, a diferencia del encontrado para el $\mathrm{pH}$, sí resultó estadísticamente diferente $(\mathrm{p}<0,05)$ para cada formulación elaborada, pudiéndose afirmar que conforme más leche de cabra posea el yogurt menor viscosidad presenta.

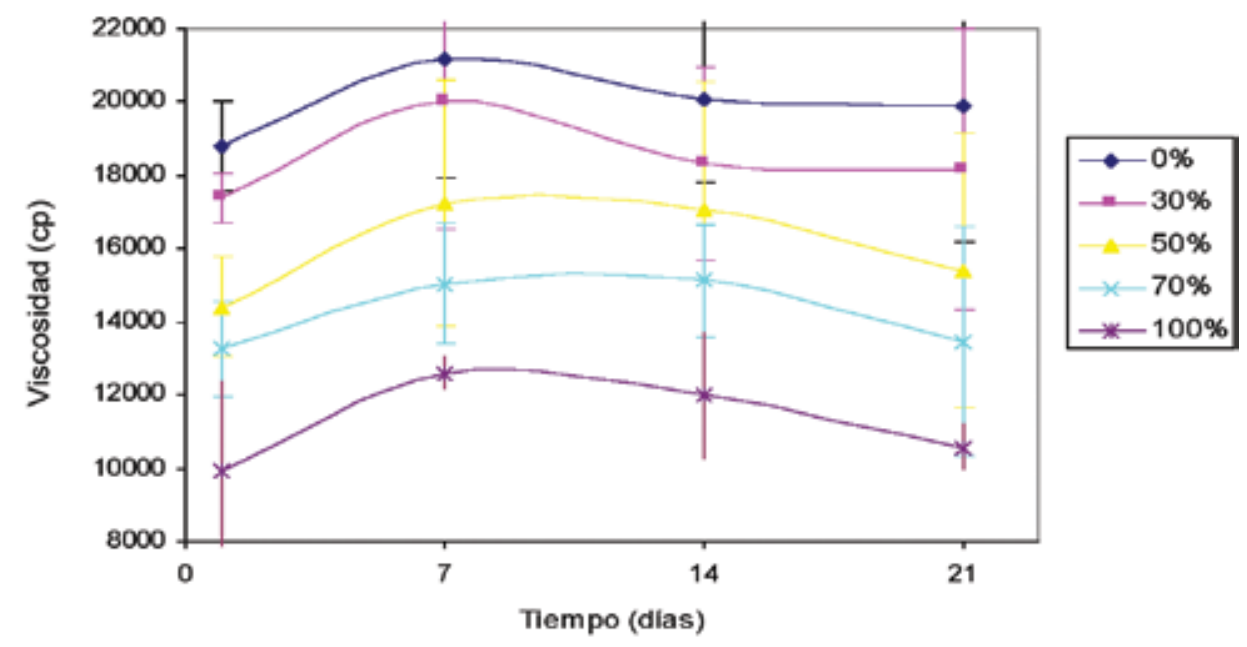

*Se presentan los intervalos de confianza al $95 \%$.

Figura 3. Comportamiento de la viscosidad medida durante el tiempo de almacenamiento del yogurt con diferente contenido de leche de cabra. San José, Costa Rica. 2005.

11 Disminución de la viscosidad dependiente del tiempo de agitación producida por un ablandamiento estructural, que se revierte al cesar el movimiento. 
De acuerdo con lo señalado por Rasic y Kurmann (1978), existe una diferencia en el tamaño y la estructura de las partículas de caseína y de los glóbulos grasos entre los diferentes tipos de leches, y esto se ve reflejado en las propiedades físicas del yogurt y su digestibilidad. Por ejemplo, la leche de cabra contiene glóbulos grasos y partículas de caseína mucho más pequeñas que la leche de vaca $(50 \mathrm{~nm}$ contra $75 \mathrm{~nm})$, lo que produce estructuras de gel poco firmes (Richardson 2004). La beta-caseína es la proteína predominante en la leche de cabra y la alfa-caseína en la leche de vaca, además, el hecho de que la alfa-s1-caseína presente en la leche de vaca esté más ausente en la de cabra, es responsable de los suaves geles que se forman a partir esta última leche (Haenlein et al. 1992).

Otro factor que afecta las propiedades físicas del gel es la inestabilidad al calor que presenta la leche de cabra lo que se relaciona con la composición de la misma. Shiv y Sindhu (1991) mencionan que la estabilidad al calor de las proteínas de la leche está determinada por el tiempo de coagulación, o sea, entre menor sea el tiempo en el cual precipitan las proteínas cuando son sometidas a un tratamiento térmico, menor será su estabilidad al calor; y el tiempo de coagulación tiende a ser más bajo entre mayor sea la cantidad de calcio disuelto en la leche. Por lo que se podría especular que la estabilidad de la leche de cabra al calor es menor que la de la leche de vaca, pues la primera puede contener más calcio que la segunda (Rodden 2004).

Richardson y Creamer (1975) afirman también que la alfa-caseína de origen caprino es más propensa a precipitar en presencia del ión calcio que la alfacaseína de origen bovino. Esto se puede relacionar con la baja viscosidad de las muestras de yogurt de leche de cabra pues, al ser las proteínas más inestables al calor, se da una mayor precipitación de las mismas durante el tratamiento térmico y se pierde parte de su capacidad para formar geles.

Debido a que el calcio, particularmente en su forma iónica, ha sido claramente identificado como el principal agente responsable de la baja estabilidad al calor de la leche de cabra, algunos autores, incluyendo Morgan et al. (2001), recomiendan el uso de secuestrantes del calcio como los fosfatos, ya que puede representar una manera eficiente de llevar a cabo el tratamiento térmico de la leche de cabra.
Estos mismos autores añaden que otro fenómeno que afecta la viscosidad del yogurt de cabra es que las caseínas caprinas alcanzan su punto isoeléctrico a pH de 4,2 en lugar de 4,6 como las de vaca, por lo tanto, cuando el yogurt tiene leche de cabra a este último $\mathrm{pH}$ no se ha alcanzado todavía el pico más alto en el desarrollo de la estructura del gel.

Todo lo anteriormente expuesto podría explicar los valores de viscosidad observados para todas las muestras. Las muestras que tienen en común la presencia de leche de cabra en su formulación presentaron baja viscosidad, que se puede atribuir en términos generales a la composición de esta leche.

En cuanto a la sinéresis, se encontró que la cantidad de suero desprendido tiende a disminuir con el tiempo de almacenamiento, para todas las muestras (Figura 4). Esto es atribuible en apariencia, a los agentes presentes en la formulación del yogurt, como es el caso de los estabilizantes, que con el tiempo tienden a "ligar" el agua embebida en la estructura del gel mejorando de manera general la hidratación de las proteínas.

Los cambios que sufren las proteínas durante la elaboración del yogurt resultan de gran importancia para la estabilidad del gel, porque están estrechamente relacionadas con el mejoramiento de la consistencia y viscosidad del producto al impedir la separación del suero ó sinéresis (Tamime y Robinson 1985). Este último factor, según Dengler y Kratz (1995), requiere especial atención, ya que la secreción de agua de la estructura del gel puede acabar con la estabilidad del yogurt, llegando a constituir uno de los peores defectos en el producto final. De ahí que la sinéresis sea un parámetro de interés, pues entre las más importantes características de calidad del yogurt se encuentra la ausencia completa de suero libre y grumos.

Podría esperarse que con el incremento en el tiempo de almacenamiento, se origine una disminución en la capacidad de retención de agua por parte de las proteínas, con el consecuente desprendimiento del suero (Schmidt et al. 1980). Sin embargo, aunque durante el tiempo de evaluación este fenómeno no fue evidente, es posible suponer que podría presentarse después de los 21 días de almacenamiento. 


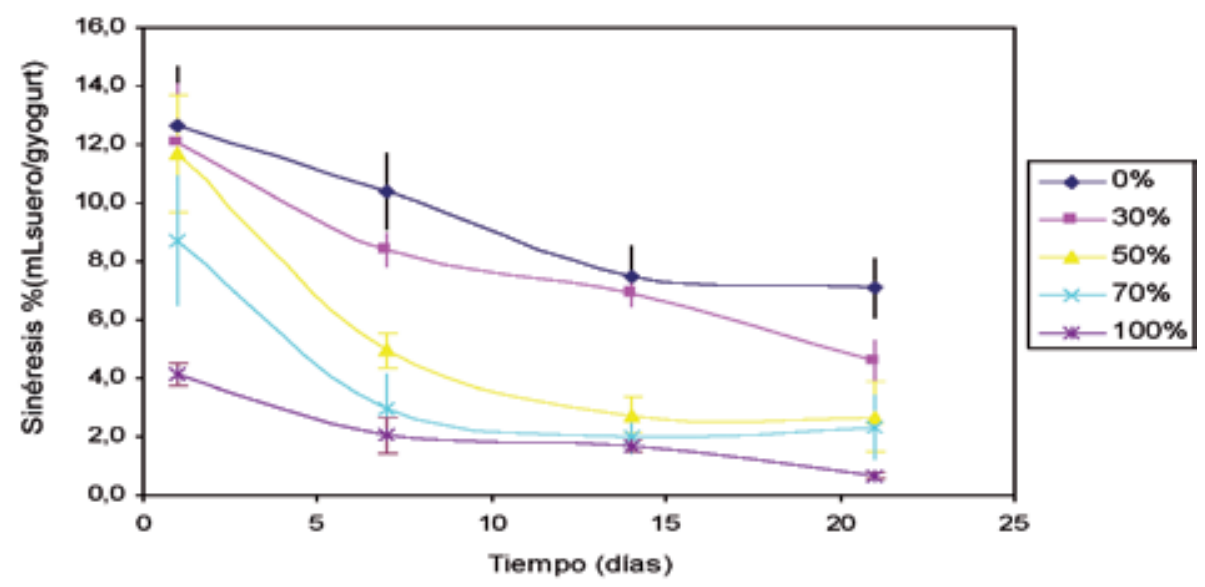

*Se presentan los intervalos de confianza al $95 \%$.

Figura 4. Comportamiento de la sinéresis medida durante el tiempo de almacenamiento del yogurt con diferente contenido de leche de cabra. San José, Costa Rica. 2005.

La muestra que presentó mayor sinéresis durante todo el periodo fue el yogurt $100 \%$ leche de vaca, mientras que el menor desprendimiento de suero lo presentó el yogurt $100 \%$ leche de cabra. Además se encontró estadísticamente una interacción significativa $(\mathrm{p}<0,05)$ entre el día de almacenamiento y el tipo de leche. Esto, quiere decir que la sinéresis tiende a disminuir a través del tiempo para todas las muestras, aunque este efecto es más marcado conforme mayor cantidad de leche de vaca posea la muestra.

La baja susceptibilidad a la sinéresis del yogurt caprino, se puede explicar nuevamente de acuerdo a su microestructura y a la composición de la leche. De acuerdo a lo señalado por Kalab (2006), gracias al pequeño tamaño de las micelas de caseína presentes en la leche de cabra, se da un aumento en la densidad de la red protéica, lo que trae consigo poros de tamaños más pequeños y habilidad de retener agua mucho más fuerte que en otros tipos de leche. Stelios y Emmanuel (2004) le atribuyen al contenido de calcio presente en la leche de cabra la capacidad de retención de agua en el yogurt, debido a interacciones iónicas en el interior de la red proteica.

Debido a la alta sinéresis en el yogurt de leche de vaca, se puede suponer que hay una mayor concentración de sólidos en la matriz del gel. Esta alta cantidad de materia suspendida está relacionada también con los elevados valores de viscosidad en este yogurt, pues se da un aumento en la interacción entre las partículas (Muller 1977).

Tanto en viscosidad como en sinéresis, se encontraron diferencias significativas $(\mathrm{p}<0,05)$ en cuanto al tipo de leche utilizada, por tal motivo se aplicó una prueba de comparación de medias de Tukey para identificar el origen de estas diferencias. Para ambos parámetros se encontró que no existen diferencias significativas $(\mathrm{p}>0,05)$ entre las muestras de $0 \%$ y $30 \%$ leche de cabra y entre las muestras $50 \%$ y $70 \%$ leche de cabra, siendo la muestra $100 \%$ leche de cabra diferente de todas las demás. El Cuadro 3 resume los resultados previamente discutidos.

\section{Evaluación sensorial de las diferentes formulacio- nes de yogurt}

Caracterización de la población estudiada según encuesta al consumidor

La población utilizada para el estudio estuvo constituida por personas que en algún momento han consumido yogurt, sin embargo, no necesariamente yogurt de leche de cabra o que acostumbren consumir 
Cuadro 3. Prueba de comparación de medias de Tukey para los valores de los parámetros de viscosidad y sinéresis. San José, Costa Rica. 2005.

\begin{tabular}{ccc}
\hline Tipo de yogurt & \multicolumn{2}{c}{ Media } \\
\cline { 2 - 3 } (\% Leche de cabra) & Viscosidad (cp) & Sinéresis (\%) \\
\hline 0 & $19979 \mathrm{a}$ & $9,4 \mathrm{~d}$ \\
30 & $18481 \mathrm{a}$ & $8,0 \mathrm{~d}$ \\
50 & $16021 \mathrm{~b}$ & $5,5 \mathrm{e}$ \\
70 & $14225 \mathrm{~b}$ & $4,0 \mathrm{e}$ \\
100 & $11277 \mathrm{c}$ & $2,1 \mathrm{f}$ \\
\hline
\end{tabular}

Promedios con letra diferente en una misma columna presentan diferencias significativas $(\mathrm{p}<0,05)$.

productos de origen caprino, pues se pretendió que el producto desarrollado fuera dirigido al mercado en general. Adicionalmente, el muestreo se realizó en la ciudad Universitaria Rodrigo Facio, e incluyó a consumidores de diversas zonas del país, tal y como lo detalla la Figura 5.

La distribución por sexo fue totalmente equitativa (50\% hombres y $50 \%$ mujeres), con lo que se evitaron sesgos por esta característica de la población. La Figura 6 muestra la distribución por edades de los panelistas.

Un segmento importante de la población encuestada estuvo constituido por jóvenes. Hoy en día se

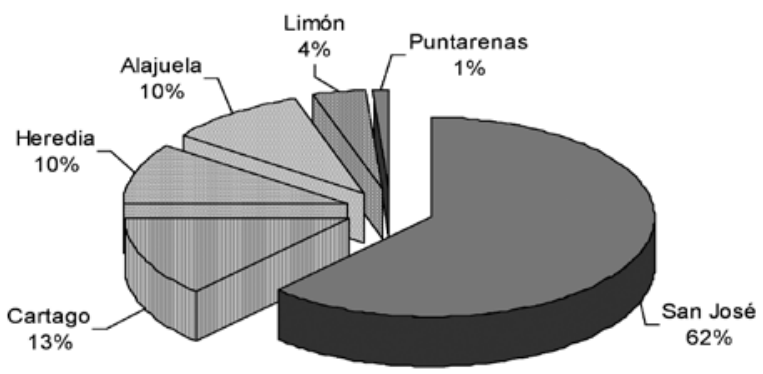

Nota: El muestreo no abarcó consumidores provenientes de la provincia de Guanacaste.

Figura 5. Distribución por lugar de residencia de los panelistas con los que se realizó la evaluación sensorial de diferentes formulaciones de yogurt San José, Costa Rica. 2005.

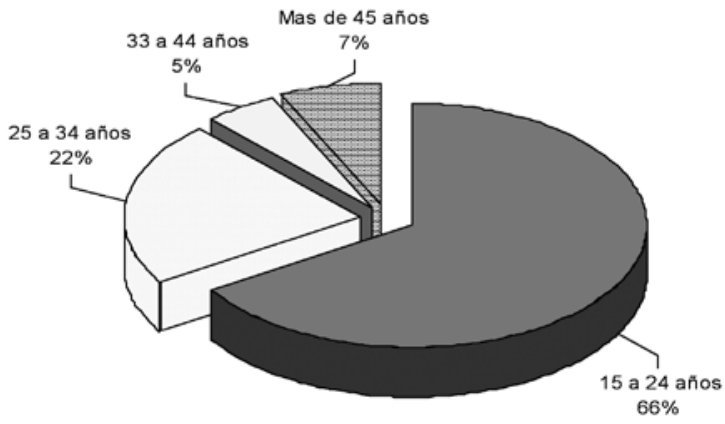

Figura 6. Distribución por edades de los panelistas con los que se realizó la evaluación sensorial de diferentes formulaciones de yogurt. San José, Costa Rica. 2005 .

encuentra en boga entre los jóvenes los productos saludables, por lo que se puede augurar que el yogurt elaborado podría resultar interesante para esta porción de la población, debido a que son individuos que en su mayoría se preocupan por la salud y el ejercicio (el $66 \%$ de los encuestados practican algún tipo de deporte). Se ha tomado más conciencia entre los jóvenes que gran parte de un estilo de vida saludable se encuentra en una buena alimentación.

Se pudo conocer mediante la encuesta al consumidor, que cerca del $91 \%$ de las personas consumen algún tipo de yogurt todos los días o frecuentemente. Aunque alrededor del $84 \%$ de las personas encuestadas nunca o casi nunca consumen leche de cabra, el producto que se desarrolló puede llegar a constituir un vehículo para introducir el consumo de la misma. Los datos correspondientes a las aseveraciones anteriores se presentan en la Figura 7.

\section{Prueba de agrado}

De acuerdo a lo mostrado en el Cuadro 4, la formulación de yogurt que resultó de menor aceptación $(\mathrm{p}<0,05)$ fue la que contenía $100 \%$ leche de cabra. Esto era previsible dado a que en Costa Rica la cultura del consumo de esta leche no está muy difundida, sobre todo en las zonas urbanas (Tacsan 1987; Corrales y Chacón 2005); y ésto se puede constatar también observando los datos de la Figura 7.

Cabe destacar que estos valores de aceptación son locales pues en otros países o regiones es popular el 


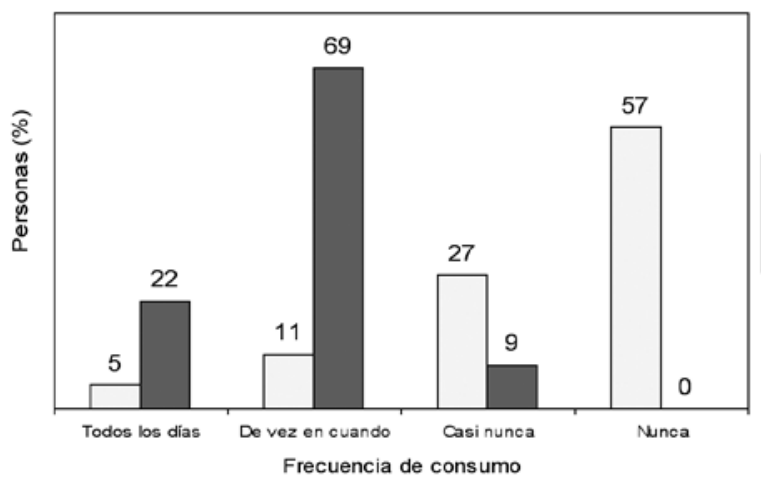

Figura 7. Frecuencia de consumo de yogurt y de leche de cabra de los panelistas con los que se realizó el estudio. San José, Costa Rica. 2005.

Cuadro 4. Prueba de comparación de medias LSD aplicada a los valores de agrado obtenidos del panel de consumidores con los que se efectuó la evaluación sensorial de diferentes formulaciones de yogurt (Valor LSD 0,58). San José, Costa Rica. 2005.

\begin{tabular}{cc}
\hline $\begin{array}{c}\text { Tipo de yogurt } \\
\text { (\% de leche de cabra) }\end{array}$ & Calificación media \\
\hline 30 & $8,1 \mathrm{a}$ \\
50 & $6,0 \mathrm{~b}$ \\
70 & $6,2 \mathrm{~b}$ \\
100 & $4,1 \mathrm{c}$ \\
\hline
\end{tabular}

Promedios con letra diferente presentan diferencias significativas $(\mathrm{p}<0,05)$.

consumo de leche de cabra y sus derivados. En otras sociedades en vías de desarrollo (por ejemplo en África), la contribución a la dieta que representa la leche de cabra es variable, llegando a constituir desde menos de $5 \mathrm{~kg}$ anuales per cápita hasta más de $450 \mathrm{~kg}$. De este último dato se desprende que para muchas personas la leche de cabra es parte fundamental de su dieta (Capra 2004). De acuerdo a ésto, se podría pensar que el agrado de este producto puede estar vinculado a un aspecto sociocultural o inclusive a la costumbre, pues el $60 \%$ de los panelistas expresaron que algunas de las muestras sabían "diferentes", lo cual no quiere decir necesariamente que sean desagradables.
Se podría recurrir a un descremado parcial de la leche destinada a la elaboración del producto, debido a que algunos ácidos grasos presentes son los responsables del aroma y en parte del sabor típicos de la leche de cabra, y mediante la sustracción parcial de estos componentes se podría conseguir aumentar el agrado del producto (Rasic y Kurmann 1978). Otra alternativa sería, tal y como recomiendan Drunkler et al. (2001), la adición de beta-ciclodextrinas, de las cuales se ha probado por medio de estudios recientes que disminuyen significativamente el "sabor a cabra" en el yogurt.

A pesar de lo anterior, el valor de agrado obtenido de 8,1 en la escala de 10 para la formulación con $30 \%$ leche de cabra fue bastante positivo. El 57\% de las personas inclusive manifestaron que el producto es muy similar a los existentes actualmente en el mercado y elaborados con leche de vaca. El 90\% de los panelistas expresaron, de hecho, que comprarían el producto.

Con estos datos se podría prever que el producto eventualmente gozaría de una buena posición en el mercado nacional, acompañado de una adecuada publicidad y mercadeo. Se podría aprovechar la producción de leche de cabra en nuestro país que, aún siendo relativamente baja (Chacón 2005) con respecto a otras regiones del mundo, sería suficiente para destinarla a la elaboración de productos como éste, y de esta forma beneficiar adicionalmente al sector caprinocultor de Costa Rica y a la población en general. Además, tal y como afirma Capra (2004), dada su factibilidad como animal lechero, se considera que el manejo adecuado y constante de lecherías basadas en la cabra representa una de las mejores estrategias para aliviar las hambrunas y combatir la desnutrición en países en vías de desarrollo, lugares donde suelen ser propicias las condiciones para pequeños rumiantes.

Por medio del análisis de varianza realizado y la prueba de comparación de medias, se pudo determinar si el agrado fue significativamente diferente entre las muestras y cuáles son las diferencias entre éstas. Se observó que las muestras de $50 \%$ y $70 \%$ de leche de cabra no presentaron diferencias significativas entre ellas $(\mathrm{p}>0,05)$, pero a su vez estas fueron diferentes $(\mathrm{p}<0,05)$ de la muestra de $30 \%$ y de la muestra de $100 \%$, que fueron las de mayor y menor agrado, respectivamente. 


\section{Prueba de aceptación}

En el Cuadro 5 aparecen los valores de aceptación dados por los jueces a los atributos de color y textura de las diferentes muestras. En cuanto al color se encontró que solamente la muestra de $70 \%$ leche de cabra no se pudo diferenciar $(\mathrm{p}>0,05)$ de las muestras de $30 \%$ y $100 \%$, las demás muestras difieren entre sí $(\mathrm{p}<0,05)$. Analizando la textura se puede observar que la aceptación de las muestras de $50 \%$ y $100 \%$ no son significativamente diferentes $(\mathrm{p}>0,05)$, sin embargo, sí se presentaron diferencias $(\mathrm{p}<0,05)$ con respecto a las otras muestras.

Cuadro 5. Prueba de comparación de medias LSD aplicada a los valores de aceptación de color y textura en el yogurt, obtenidos del panel de consumidores con los que se efectuó la evaluación sensorial de diferentes formulaciones de yogurt (Valores LSD 0,24 y 0,23, respectivamente). San José, 2005.

\begin{tabular}{ccc}
\hline \multirow{2}{*}{$\begin{array}{c}\text { Tipo de yogurt } \\
\text { (\% Leche de cabra) }\end{array}$} & \multicolumn{2}{c}{ Media (Ideal=3) } \\
\cline { 2 - 3 } & Color & Textura \\
\hline 30 & $2,84 \mathrm{~b}$ & $3,38 \mathrm{~d}$ \\
50 & $2,45 \mathrm{c}$ & $2,88 \mathrm{ab}$ \\
70 & $3,11 \mathrm{a}$ & $2,42 \mathrm{f}$ \\
100 & $2,70 \mathrm{e}$ & $2,20 \mathrm{f}$ \\
\hline
\end{tabular}

Promedios con letra igual no presentan diferencias significativas $(\mathrm{p}>0,05)$.

Observando el Cuadro 5, las muestras de 30\%, $50 \%$ y $70 \%$ presentaron valores de aceptación del color inferiores pero cercanos al valor ideal de 3 (VI). Los jueces catalogaron estas muestras como más claras que el color deseado y la muestra de $100 \%$ más oscura. La única muestra que se aleja más del VI de aceptación es la de $50 \%$ que resultó ser más clara que el VI. Lo mismo sucede en el caso de la textura. Las muestras de $50 \%, 70 \%$ y $100 \%$ resultaron con una textura más baja que el VI y la muestra de $30 \%$ más viscosa. A pesar de esto, las muestras de $50 \%$ y $100 \%$ son las que más se alejaron del VI, siendo consideradas menos viscosas de acuerdo a la apreciación de los jueces.
Estos resultados coinciden con lo obtenido en forma experimental, pues efectivamente las muestras de yogurt con una viscosidad baja fueron los elaborados con leche de cabra. Y, precisamente, quizás sea por esta razón que el yogurt 100\% leche de cabra fue apreciado como más oscuro, pues al ser menos viscoso se hace más fácil la dispersión del topping y el color se distribuye más homogéneamente.

En términos generales, los resultados obtenidos del nivel de aceptación del color y la textura del yogurt fueron buenos, pues todos los valores otorgados por los jueces se encontraron muy cercanos al VI de 3 de la escala Justo-Correcto. Con esto se corrobora que el bajo nivel de agrado obtenido por algunas muestras se debe al sabor y no a otros atributos como la apariencia y la textura del yogurt.

\section{Escogencia de la formulación más conveniente}

Para la escogencia del producto se tomó en cuenta la evaluación sensorial realizada con los consumidores, por lo que se eligió el producto elaborado con $30 \%$ leche de cabra al ser el de mayor agrado, según la población estudiada. No obstante, al inclinarse por esta formulación, no se están dejando de lado ciertas ventajas desde el punto de vista técnico y nutricional enunciadas en la literatura para yogurt natural batido (Haenlein 2002; Haenlein et al. 1992; Rasic y Kurmann 1978; Spreer 1998; Tamime y Deeth 1980 y Tamime y Robinson 1985).

El yogurt $30 \%$ leche de cabra no sólo presenta la ventaja de una adecuada aceptación entre los panelistas. Posee, gracias a la cantidad de leche de cabra, una sinéresis durante el almacenamiento más baja que el yogurt elaborado sólo con leche de vaca. Este fenómeno responde a varios factores como microestructura y composición de la leche de cabra que permiten mantener una buena capacidad de retención de agua.

Manifiesta, además, una viscosidad tan buena como la del yogurt de leche de vaca, pues de acuerdo al estudio realizado no existen diferencias significativas $(p>0,05)$ entre estas muestras para el parámetro mencionado. Esto quiere decir que los aspectos discutidos con anterioridad sobre la composición de la leche 
de cabra y su influencia en la viscosidad del yogurt no tienen efectos significativos $(\mathrm{p}>0,05)$.

Por último, se pueden aprovechar, aunque en forma parcial, los múltiples beneficios para la salud y nutrición humana que se obtienen del consumo de leche de cabra (Crawford 2004).

\section{LITERATURA CITADA}

ASEAL. 2004a. Product information: FD-DVS YC-X11. Aseal S.A., San José. 2 p.

ASEAL. 2004b. Hoja técnica del yogurt batido: FD-DVS YC-X11. Aseal S.A., San José. 2 p.

A.O.A.C. (Association of Official Analytical Chemistry). 1990. Official methods of analysis. 15 ed. Association of Official Analytical Chemistry. Washington D.C., USA. 1298 p.

BILLE, P.; VOVOR, M.; GORESEB, J.; KEYA, E. 2000. Evaluating the feasibility of adding value to goat's milk by producing yoghurt using low cost technology method for rural Namibia. Journal of Food Technology in Africa 5(4): 13-21.

BRITO, M. 2000. Leche: alimento indispensable (en línea). Consultado 26 jul. 2006. Santiago, Chile. Disponible en: www.tetrapak.cl.

BUTTRISS, J. 1997. Nutritional properties of fermented milk products. International Journal of Dairy Technology 50(1): 21-27.

CAPRA. 2004. La composición de la leche de cabra y su papel en la alimentación humana (en línea). Consultado 16 nov. 2004. Madrid, España. Disponible en: http://www. iespana.es/ CAPRA/HOMBRE/HOMBRE.HTM

CARVAJAL, N. 1999. Estudio del efecto del uso de cultivos probióticos en la elaboración de un producto similar al yogurt. Tesis Lic. en Tecnología de Alimentos. Escuela de Tecnología de Alimentos. Universidad de Costa Rica. 65 p.
CHACÓN, A. 2003. La elaboración del queso fresco y otros derivados lácteos: guía básica artesanal y de la pequeña industria. Ed. Universidad de Costa Rica. San Pedro de Montes de Oca, San José. 66 p.

CHACÓN, A. 2004. Estudio de la acidez titulable y el peso específico de la leche de cabra de un grupo de capricultores de la Meseta Central Costarricense. Agronomía Mesoamericana 15(2): 179-183.

CHACÓN, A. 2005. Aspectos nutricionales de la leche de cabra y sus variaciones en el proceso agroindustrial. Revista Agronomía Mesoamericana 16(2): 239-252

CORRALES, J.; CHACÓN, A. 2005. Estudio de opinión de consumidores sobre el queso fresco de cabra (Capra hircus) en Costa Rica. Revista Agronomía Tropical 35: 39-49.

CLAVERÁN, M. 1993. Fruta preparada para yogurt. Industria Alimentaria 15(4): 32-34.

CRAWFORD, F. 2004. Yogurt: alimento poderoso (en línea). Consultado 16 nov. 2004. Cuernavaca, México. Disponible en: www. williams-cuernavaca.edu.mx.

DENGLER, K.; KRATZ, R. 1995. Fruit Preparations for Yoghurts. Food Tech Europe 2(2): 130-137.

DOSTALOVA, J. 1994. Goats’ Milk. Vyziva 49(2): 43-44.

DRUNKLER, D., FETT, R.; LUIZ, M. 2001. Utilization of beta-cyclodextrin for minimization of "goaty flavour" of yoghurt from goat milk. Boletim do Centro de Pesquisa e Processamento de Alimentos 19(1): 13-22.

FARNSWORTH, J.; HENDRICKS, G.; GOTCHEVA, V.; AKUZAWA, R.; GUO, M. 2002. Effects of enzymatic crosslinking on the consistency and structure of probiotic goat milk yogurt. Journal of Dairy Science 85(Suppl.1): 120.

FERRARO, V. 1982. Sabores de yogurt: es cuestión de gustos. Industrias Lácteas 31(6): 34-38.

HAENLEIN, G. 2002. Composition of goat milk and factors affecting it (en línea). Consultado 26 nov. 
2004. Delaware, Estados Unidos. Disponible en: http://ag.udel.edu/extension/information/goatmgt/gm09.htm

HAENLEIN, G., CACCESE, R.; DELAWARE, U. 1992. National goat handbook (en línea). Consultado 26 jul. 2006. Maryland, Estados Unidos. Disponible en: http://outlands.tripod.com/farm/national_goat_handbook.pdf.

HIRANO, R.; HIRANO, M.; OOOKA, S.; DOSAKO, S.; NAKAJIMA, I.; IGOSHI, K. 1998. Lactoperoxidase effects on rheological properties of yogurt. Journal of Food Science 63(1): 35-37.

HORST, A.; WITTIG, E.; HARPE, R.; LÓPEZ, L. 1995. Empleo de cultivos de acidificación suave en la elaboración de yogurt. Tecnología Láctea Latinoamericana 136: 42-45.

JAY, J. 1994. Microbiología moderna de los alimentos. 4 ed. Acribia. Zaragoza. España. 804 p.

KALAB, M. 2006. Yoghurt: electron microscopy (en línea). Consultado 26 julio 2006. Londres, Inglaterra. Disponible. http://www.magma.ca/ pavel/science/ Yogurt.htm

KARAGUL-YUCEER, Y.; WILSON, J.C.; WHITE, C.H. 2001. Formulations and processing of yogur affect the microbial quality of carbonated yogurt. Journal Dairy Science 84(1): 543-550.

KEATING, P.; GAONA, H. 1999. Introducción a la Lactología. 2 ed. Limusa, México, D.F. 316 p.

LEWIS, M. 1993. Propiedades físicas de los alimentos y de los sistemas de procesado. Acribia, Zaragoza. España. $494 \mathrm{p}$.

MERIN, U. 2000. Influence of breed and husbandry on viscosity of Israeli goat milk yogurt. Small Ruminant Research 35(2): 175-179.

MORA, L. 1994. Evaluación del efecto del contenido de sólidos lácteos y de la velocidad de enfriamiento sobre las características del yogurt natural batido. Tesis Lic. en Tecnología de Alimentos. Escuela de Tecnología de Alimentos. Universidad de Costa Rica. 77 p.

MORGAN, F.; MICAULT, S.; FAUQUANT, J. 2001. Combined effect of whey protein and alpha-casein genotype on the heat stability of goat milk. International Journal of Dairy Technology 54(2): 64-87.

MULLER, H. 1977. Introducción a la reología de los alimentos. Acribia, Zaragoza. España. 174 p.

NORAT, T.; RIBOLI, E. 2003. Dairy Products and Colorectal Cancer. European Journal of Clinical Nutrition 57(1): 1-17.

PALENCIA, Y. 2004. Los alimentos lácteos y sus limitaciones (en línea). Consultado 26 julio 2006. Zaragoza, España. Disponible en: http://www.unizar. es/med_naturista/Lacteos.pdf

PERDIGON, G.; LeBLANC, A.; VALDEZ, J.; RACHID, M. 2002. Role of yogurt in the prevention of colon cancer. European Journal of Clinical Nutrition 56(8): S65-S68.

POSECION, N.C.; CROWE, N.L.; ROBINSON, A.R.; ASIEDU, S.K. 2005. The development of a goat's milk yogurt. Journal of the Science of Food and Agriculture 85(11): 1909-1913.

RAO, D.R.; ALHAJALI, A.; CHAWAN, C.B. 1987. Nutritional, sensory and microbiological qualities of labneh made from goat milk and cow milk. Journal of Food Science 52(5): 1228-1230.

RASIC, J.; KURMANN, J. 1978. Yogurt: scientific grounds, technology, manufacture and preparations: technical Dairy Publishing. Copenhagen. 466 p.

RICHARDSON, C. 2004. Let's learn about dairy goats and goat's milk (en línea). Consultado 26 jul. 2006. Oklahoma, Estados Unidos. Disponible en: www.clover.okstate.edu/fourh/newpage/ projects/4h424.pdf.

RICHARDSON, B.; CREAMER, L. 1975. Comparative micelle structure: the similarity between caprine alpha-casein and bovine alpha-casein. Biochemical and Biophysical Acta 393(1): 37-47. 
RODDEN, D. 2004. Dairy goat composition (en línea). Consultado 26 julio 2006. Davis California, Estados Unidos. Disponible en: http://drinc.ucdavis.edu/ goat1_new.htm

RODRÍGUEZ, J.; RODRÍGUEZ, I.; HOMBRE, R. 1994. Términos empleados en la evaluación sensorial de la textura de alimentos. Ciencia y Tecnología de Alimentos 4(2): 40 .

SABBAG, N.; GOSTA, S. 1995. Aceptabilidad sensorial de cuatro sabores de yogurt. La Alimentación Latinoamericana 209: 60-64.

SÁENZ, G. 1984. Procesamiento de frutas para yogurt. Tesis Lic. en Tecnología de Alimentos. Escuela de Tecnología de Alimentos. Universidad de Costa Rica. 106 p.

SAINT-EVE, A.; LEVY, C.; MARTIN, N.; SOUCHON, I. 2006. Influence of proteins on the perception of flavored stirred yogurs. Journal of dairy Science 89(1): 922-933.

SHERMAN, P. 1979. Food texture and rheology. Academic Press, London. 265 p.

SHIV, R.; SINDHU, J. 1991. Salt balance and heat stability of goat milk as affected by $\mathrm{pH}$. Indian Journal of Animal Sciences 61(7): 753-756.

SHOEMAKER, C.; NANTZ, J.; BONNANS, S.; NOBLE, A. 1992. Rheological characterization of dairy products. Food Technology 46(1): 98-104.

SCHMIDT, R.; SISTRUNK, C.; COMELL, J. 1980. Heat treatment and storage effects on texture characteristics of milk and yogurt systems fortified with oilseeds proteins. Journal of Food Science 45(3):471.

SPREER, E. 1998. Milk and dairy product technology. Marcel Dekker Inc., New York. 483p.

STEINER, I.; VOLANSKY, P. 2003. Modelling migrants from plastics into foodstuffs as a novel and cost efficient tool for estimation of consumer exposure from food contact materials (en línea). Consultado
1 ago. 2006. Viena, Austria. Disponible: http://www. foodmigrosure.com/html/Deliverable1\%20plus.pdf

STELIOS, K.; EMMANUEL, A. 2004. Caprine, ovine and caprine-ovine yoghurts. International Journal of Food Science and Technology 39(1): 319-324.

TACSAN, I. 1987. Fabricación de un queso de leche de cabra tipo crottin adaptado al gusto costarricense. Tesis Lic. en Tecnología de Alimentos. Universidad de Costa Rica, Escuela de Tecnología de Alimentos. San José. $83 \mathrm{p}$.

TAMIME, A.; DEETH, H. 1980. Yogurt: technology and biochemistry. Journal of Food Protection 43(12): 939-973.

TAMIME, A.; ROBINSON, R. 1985. Yoghurt: science and technology. Pergamon Press. Gran Bretaña. 431 p.

UYSAL, H.; KILIC, S.; KAVAS, G.; AKBULUT, N.; KESENKAS, H. 2003. Some properties of set yoghurt made from caprine milk and bovine-caprine milk mixtures fortified by ultrafiltration or the addition of skim milk powder. International Journal of Dairy Technology 56(3): 177-185.

VILLANUEVA, N.; DA SILVA, M.; PETENATE, A. 2002. Performance of the hybrid and self-adjusting hedonic scales in the generation of internal preference maps (en línea). Consultado 26 jul. 2006. Anaheim, California. Disponible en: http://ift.confex.com/ift/2002/techprogram/paper_13714.htm

WATTS, B.; YLIMAKI, G.; JEFFERY, L.; ELÍAS, L. 1992. Métodos sensoriales básicos para la evaluación de alimentos. Centro Internacional de Investigaciones para el Desarrollo. Ottawa, Canada. 171 p.

WETHERBEE, K. 2002. Want milk?: Get goats. Mother Earth News. 192: 30.

WHITE, P. J. 2002. Recent advances in fruit development and ripening: an overview. Journal of Experimental Botany 53(377): 1995-200. 